\title{
Values for function in rheumatoid arthritis: patients, professionals, and public
}

\author{
S Hewlett, A P Smith, J R Kirwan
}

\begin{abstract}
Background-Although many disability questionnaires measure fact very efficiently, they do not allow for consideration of the relevance of that disability to the patient. Data suggest that professionals misinterpret the relevance of disability for the patient and thus, also, the outcome of treatment.
\end{abstract}

Objectives-Firstly, to examine agreement on levels of importance for the items on a validated disability scale (Health Assessment Questionnaire (HAQ) and Modified HAQ (MHAQ)), within groups of patients with rheumatoid arthritis, health professionals, and controls. Secondly, to see if functional items important to patients are included in the HAQ, and whether the HAQ items are important to patients.

Methods-25 patients with RA, 25 rheumatology health professionals, and 25 healthy controls were asked to rate the importance of the HAQ (20 items) and MHAQ (eight domains). Before seeing the HAQ, patients were asked to generate items of function important to them.

Results-Only a slight-fair agreement within each group was found for the level of importance of the HAQ and MHAQ, and also within any combination of the groups ( $\kappa$ values $<0.38$ ). Most of the functional items valued by patients were contained on the HAQ (70\%), and no HAQ items were consistently rated as unimportant.

Conclusion-Patients, professionals, and healthy controls do not agree on the importance of disabilities. These data support the need to assess the personal impact of disability, as well as disability itself. Individual importance of disability weighted by level of disability is proposed as a model for calculating the personal impact of disability. A new tool to assess the personal impact of disability is being developed.

(Ann Rheum Dis 2001;60:928-933)

Royal Infirmary, UK

$S$ Hewlett

J R Kirwan

School of Psychology, Cardiff University, UK A P Smith

Correspondence to: Dr S Hewlett, University of Bristol Rheumatology Academic, Bristol Royal Infirmary, Bristol BS2 8HW, UK

Sarah.Hewlett@bristol.ac.uk

Accepted 4 April 2001 increases, ${ }^{3}$ and the measurement of disability (or activity limitation as opposed to impairment at tissue level) ${ }^{4}$ is now a well validated come measures, such as function or physic toid arthritis (RA) is often high at presentation, science, commonplace in clinical practice and research. The Health Assessment Questionnaire (HAQ) is a self reporting tool that measures disability in arthritis and correlates well with observed performance. ${ }^{15}$ It has been widely reviewed, its use is widespread, and it is recommended as a core measure in trials..$^{6-8}$

Many disability questionnaires measure fact efficiently using approaches such as, "I have much difficulty climbing stairs", and are not intended to measure the impact of these facts on the individual patient. However, disabilities such as climbing stairs, for example, may be of little importance to someone living in a bungalow but of major concern to someone with an upstairs bathroom. The differing impact of disability on individual patients may be one explanation for the relatively modest associations reported between level of disability and dissatisfaction with disability, ${ }^{9-11}$ for the discrepancy between clinicians and patients on disability levels, ${ }^{12}{ }^{13}$ and for the relatively poor association between actual (calculated) change in disability and patient perception of change. ${ }^{14}{ }^{15}$ Large changes in functions of little personal relevance and small changes in functions of great personal relevance may account for these results. Activities that are rated by patients with RA as difficult and important are associated with reduced psychological wellbeing, and stopping $10 \%$ or more of such activities is a predictor of depression. ${ }^{16-18}$ A measure of disability impact, based on personal importance and used in addition to a measure of disability, would therefore be useful, allowing patients and clinicians to place a disability score within an individual context.

Attempts have been made to incorporate relevance to patients in outcome measures by using mean importance weightings derived from professionals or from the general population. ${ }^{19-21}$ Mean weightings assume agreement between patients' views and the group from whom the mean is calculated, but a growing body of evidence suggests that patients' views about the importance of aspects of illness differ from those of clinicians and controls. Studies have shown that doctors' ratings of their patients' quality of life and their most important health domains differ significantly from their patients' views. ${ }^{22}{ }^{23}$ Differences of opinion about the value of self management activities or functions have been found between patients and professionals and between patients and controls, ${ }^{24}{ }^{25}$ and people who use wheelchairs rate the importance of abilities that they lack significantly lower than do controls. ${ }^{26}$ Whereas some studies show no significant difference between ratings given to quality of life situations by patients with RA 
Table 1 Demographic data ( $n=25$ in each group)

\begin{tabular}{llll}
\hline & Mean & SD & Range \\
\hline $\begin{array}{llll}\text { Patients with RA } \\
\quad \text { Age (years) }\end{array}$ & 58.6 & 16.6 & $20-82$ \\
$\quad \begin{array}{l}\text { Disease duration (years) } \\
\begin{array}{l}\text { Disability (HAQ) } \\
\text { Controls }\end{array}\end{array}$ & 16.7 & 10.8 & $1-42$ \\
$\quad$ Age (years) & 2.16 & 0.36 & $1.5-2.75$ \\
$\begin{array}{l}\text { Health professionals } \\
\quad \text { Rheumatology experience (years) }\end{array}$ & 7.64 & 4.7 & $1-17$ \\
$\quad$ HAQ experience (years) & 5.5 & 3.6 & $0-13$ \\
\hline
\end{tabular}

and controls, ${ }^{27}$ one such tool (EuroQol) is reported to perform poorly in patients with $\mathrm{RA},{ }^{28}$ though it is designed to examine groups and thus uses general population social tariffs. Even if importance weightings for disability are calculated using means from patient views, this assumes that patients agree with each other. However, two studies report that patients whose HAQ scores are very similar (differing by only $0.19-0.22$ out of 3) rate themselves as clearly different from each other. ${ }^{29}{ }^{30}$ Thus there seems an a priori case for using individual rather than mean weightings, but this has not always been the case in published scales to date, perhaps because of lack of firm evidence of a difference in disability values.

All but one of the above studies report considerable differences in the rating of disability, the importance of symptoms, and the clinical significance of different functional states between patients and professionals, controls, and other patients. This suggests that a measure of the different impact that disability has for individual patients would provide useful information to be used alongside the standard disability measure. The main aim of this study is to ascertain whether a mean weighting system would be appropriate, by examining levels of agreement on importance for the items on a common disability scale within groups of patients with RA, health professionals, and non-arthritic controls. If an existing tool can be used to calculate a new measure of the personal

Table 2 Frequency of importance scores for 20 Health Assessment Questionnaire activities of daily living (HAQ ADLs) ( $n=25$ in each group)

\begin{tabular}{|c|c|c|c|c|c|c|c|c|c|c|c|c|}
\hline \multirow[b]{2}{*}{$A D L$} & \multicolumn{4}{|c|}{ Health professionals } & \multicolumn{4}{|c|}{$\begin{array}{l}\text { Patients with rheumatoid } \\
\text { arthritis }\end{array}$} & \multicolumn{4}{|c|}{ Non-arthritic controls } \\
\hline & 0 & 1 & 2 & 3 & 0 & 1 & 2 & 3 & 0 & 1 & 2 & 3 \\
\hline Dress & 0 & 1 & 4 & 20 & 0 & 1 & 4 & 20 & 0 & 0 & 3 & 22 \\
\hline Shampoo hair & 0 & 12 & 11 & 2 & 4 & 3 & 9 & 9 & 1 & 0 & 6 & 18 \\
\hline Rise (chair) & 0 & 7 & 9 & 9 & 3 & 4 & 11 & 7 & 5 & 2 & 5 & 13 \\
\hline Rise (bed) & 0 & 0 & 4 & 21 & 1 & 3 & 16 & 15 & 0 & 0 & 3 & 22 \\
\hline Cut meat & 3 & 6 & 10 & 6 & 5 & 3 & 9 & 8 & 1 & 2 & 4 & 18 \\
\hline Lift cup & 1 & 0 & 7 & 17 & 2 & 2 & 9 & 12 & 0 & 0 & 3 & 22 \\
\hline Open carton & 5 & 11 & 5 & 4 & 3 & 8 & 6 & 8 & 1 & 5 & 6 & 13 \\
\hline Walk (flat) & 0 & 1 & 12 & 12 & 1 & 1 & 9 & 14 & 1 & 2 & 3 & 19 \\
\hline Stairs & 0 & 7 & 10 & 8 & 1 & 3 & 9 & 12 & 1 & 1 & 6 & 17 \\
\hline Wash body & 0 & 1 & 10 & 14 & 0 & 1 & 5 & 19 & 0 & 0 & 3 & 22 \\
\hline Bath & 1 & 6 & 11 & 7 & 3 & 3 & 3 & 16 & 0 & 0 & 3 & 22 \\
\hline On/off toilet & 0 & 0 & 0 & 25 & 0 & 0 & 4 & 21 & 0 & 0 & 0 & 25 \\
\hline Reach up & 11 & 10 & 4 & 0 & 9 & 5 & 5 & 6 & 4 & 3 & 7 & 11 \\
\hline Reach down & 1 & 16 & 5 & 3 & 1 & 6 & 7 & 11 & 0 & 3 & 9 & 13 \\
\hline Open car door & 6 & 13 & 4 & 2 & 5 & 7 & 4 & 9 & 2 & 4 & 6 & 13 \\
\hline Open jars & 0 & 10 & 8 & 7 & 1 & 8 & 10 & 6 & 3 & 3 & 8 & 11 \\
\hline Turn taps & 1 & 2 & 9 & 13 & 1 & 2 & 0 & 12 & 0 & 1 & 6 & 18 \\
\hline Shops & 1 & 9 & 10 & 5 & 2 & 2 & 7 & 14 & 0 & 2 & 5 & 18 \\
\hline In/out car & 0 & 6 & 14 & 5 & 5 & 2 & 8 & 10 & 1 & 3 & 7 & 14 \\
\hline Chores & 2 & 10 & 9 & 4 & 2 & 3 & 8 & 12 & 1 & 2 & 5 & 17 \\
\hline \multirow{2}{*}{$\begin{array}{l}\text { Total } \\
\text { Proportion of } \\
\text { group }(\%)\end{array}$} & 32 & 128 & 156 & 184 & 49 & 67 & 143 & 241 & 21 & 33 & 98 & 348 \\
\hline & 6.4 & 25.6 & 31.2 & 36.8 & 9.8 & 13.4 & 28.6 & 48.2 & 4.2 & 6.6 & 19.6 & 69.6 \\
\hline
\end{tabular}

impact of disability it must include functions important to patients and exclude unimportant functions. The most common disability measure (HAQ) appropriately uses items selected for their ability to measure function, ${ }^{1}$ and therefore the second aim of the study is to examine whether items of importance generated by patients are included in the HAQ, and whether any HAQ items are unimportant to patients.

\section{Methods}

Thirty one rheumatology health professionals from a variety of professions, locations, and backgrounds (clinical and academic) were invited to complete the questionnaire, with five local professionals completing them as structured interviews. They were asked to rate the importance of the 20 items on the $\mathrm{HAQ}^{1}$ and the eight domains on the Modified $\mathrm{HAQ}^{9}$ in response to the question: "Some questionnaires use healthcare professionals' values to weight patient centred scales. Could you tick a column for each of the HAQ questions to show the value or importance level you think they hold for the patient?" (not at all important, a little, quite, very important, $0-3$ ). The HAQ comprises 20 activity of daily living questions (ADLs), grouped into eight functional categories. Level of difficulty over the previous week is recorded (no difficulty, some difficulty, much difficulty, or unable to do, 0-3) and aids or assistance required. The eight category scores are summed and averaged, yielding a disability score of $0-3$, where 3 is extreme disability. The Modified HAQ (MHAQ) of Pincus et al uses eight of the ADLs to represent the 20 item version. ${ }^{9}$ To try to capture more of the HAQ functions while maintaining the brevity of the MHAQ questionnaire, the wording of some of the eight ADLs selected by Pincus was expanded slightly (into domains) to incorporate the missing ADLs.

Twenty eight consecutive inpatients with confirmed $\mathrm{RA}^{31}$ were invited to take part and interviewed using a structured format. Inpatients were used in order to find patients with high disability, as to ask patients about values for non-existent disabilities would have been an abstract question. Before being shown an HAQ, patients were asked to generate physical functions they considered personally important in response to the question: "Some people with arthritis have difficulties physically doing everyday things. When you think about your ability to do things in everyday life, what one thing bothers or upsets you the most?" Patients were then asked to place a personal value on their generated items, and on the 20 ADLs of the HAQ and the eight domains of the MHAQ in response to the question: "I would like to find out how important this is to you, or how much you value it. For example, someone who lives in a bungalow may have difficulty climbing stairs but that might not be important to them" (not at all important, a little, quite, very important, 0-3). Patients then completed an HAQ.

Fifty non-arthritic controls, primarily lay friends of colleagues, were invited to take part 
Table 3 Frequency of importance scores for eight modified Health Assessment Questionnaire (MHAQ) domains ( $n=25$ in each group)

\begin{tabular}{|c|c|c|c|c|c|c|c|c|c|c|c|c|}
\hline \multirow[b]{2}{*}{ Category } & \multicolumn{4}{|c|}{ Health professionals } & \multicolumn{4}{|c|}{$\begin{array}{l}\text { Patients with } \\
\text { rheumatoid arthritis }\end{array}$} & \multicolumn{4}{|c|}{$\begin{array}{l}\text { Non-arthritic } \\
\text { controls }\end{array}$} \\
\hline & 0 & 1 & 2 & 3 & 0 & 1 & 2 & 3 & 0 & 1 & 2 & 3 \\
\hline Dress/groom & 0 & 1 & 3 & 21 & 0 & 1 & 3 & 21 & 0 & 0 & 0 & 25 \\
\hline Rise from bed/chair & 0 & 1 & 8 & 16 & 0 & 2 & 7 & 16 & 0 & 0 & 3 & 22 \\
\hline Eat and prepare food & 1 & 1 & 8 & 15 & 0 & 3 & 8 & 14 & 0 & 0 & 5 & 20 \\
\hline Walk/stairs & 0 & 1 & 9 & 15 & 3 & 0 & 4 & 18 & 0 & 0 & 3 & 22 \\
\hline Hygiene/toilet & 0 & 0 & 1 & 24 & 0 & 1 & 2 & 22 & 0 & 0 & 0 & 25 \\
\hline Reach up/down & 2 & 9 & 11 & 3 & 1 & 4 & 10 & 10 & 0 & 1 & 9 & 15 \\
\hline Grip & 1 & 6 & 10 & 8 & 0 & 5 & 7 & 13 & 0 & 1 & 8 & 16 \\
\hline Activity (general) & 0 & 10 & 9 & 6 & 1 & 4 & 11 & 9 & 0 & 2 & 4 & 19 \\
\hline Total & 4 & 29 & 59 & 108 & 5 & 20 & 52 & 123 & 0 & 4 & 32 & 164 \\
\hline Proportion of group (\%) & 2 & 14.5 & 29.5 & 54 & 2.5 & 10 & 26 & 61.5 & 0 & 2 & 16 & 82 \\
\hline
\end{tabular}

$0=$ not at all important, 1 = a little important, $2=$ quite important, 3 = very important.

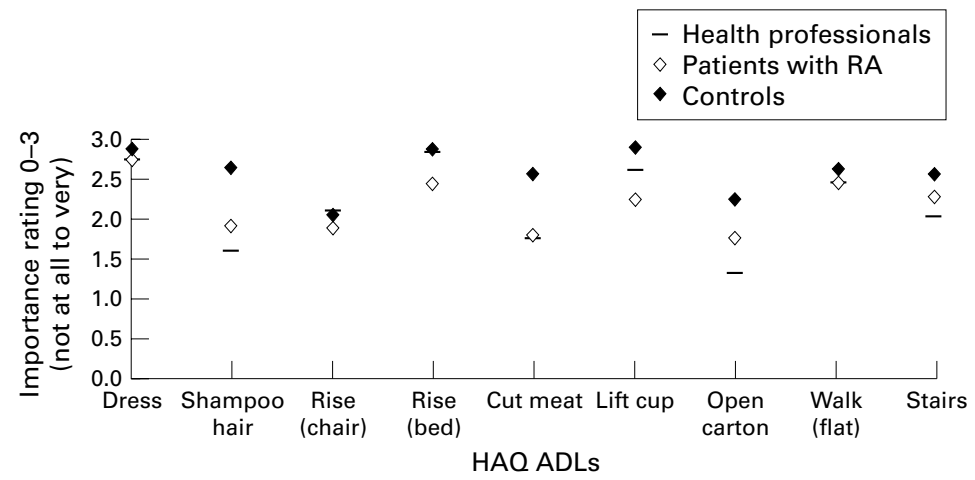

Figure 1 Mean importance rating for 20 Health Assessment Questionnaire activities of daily living (HAQ ADLs; ADLs 1-9). $0-3=$ not at all to very important ( $n=25$ in each group).

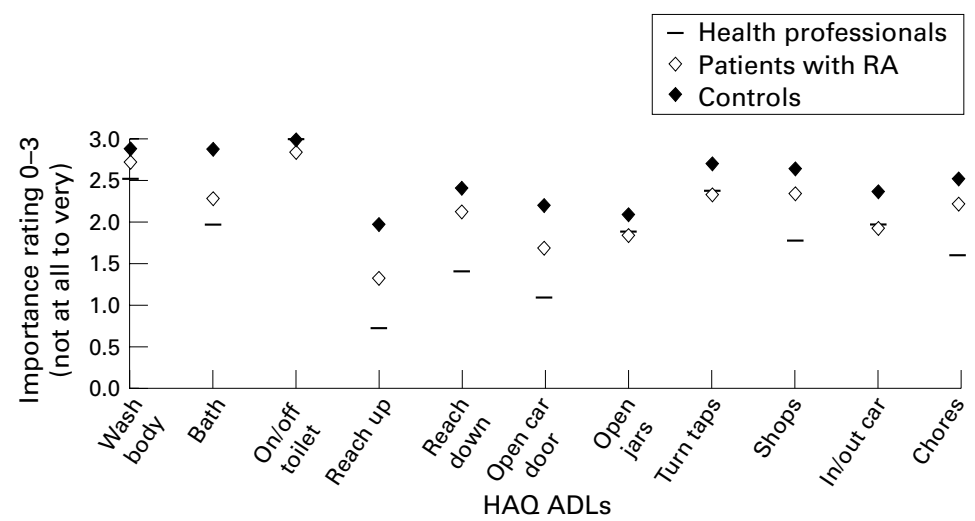

Figure 2 Mean importance rating for 20 Health Assessment Questionnaire activities of daily living (HAQ ADLs; ADLs 10-20). $0-3=$ not at all to very important $(n=25$ in each group).

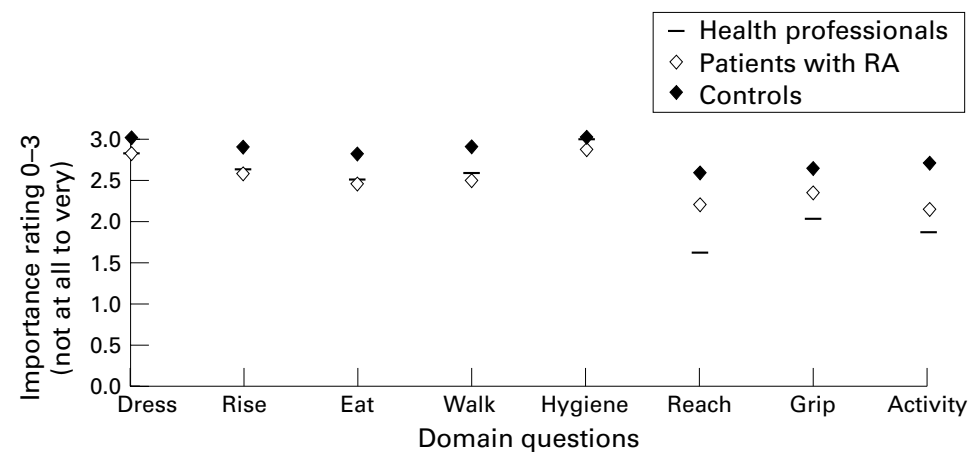

Figure 3 Mean importance rating for the eight domains of the Modified Health Assessment Questionnaire (MHAQ).0-3 = not at all to very important ( $n=25$ in each group). in a postal questionnaire and rate the importance of the 20 ADLs of the HAQ and the eight domains of the MHAQ in the same manner. For all groups the 20 ADLs and eight domain versions were presented in random order and items were also listed randomly to reduce any order effect. Ethical approval for the study was obtained from the local research ethics committee.

\section{STATISTICS}

Descriptive statistics are used for the patient generated items and importance ratings for functions. Simple $\kappa$ values and quadratic weighted $\kappa$ values (measured using intraclass correlation coefficients) are used to measure agreement within different groups for the importance of the overall HAQ scores and the overall MHAQ scores. $^{32}$ s3 $^{33}$

\section{Results}

Twenty five patients with RA, 25 rheumatology health professionals, and 25 non-arthritic controls agreed to take part. Both patients and professionals had considerable personal or professional experience of RA, and only one professional had no personal experience of the HAQ (table 1). Patients and controls were of a similar age, and patients included 17 women (health professionals 20, controls 16). Patients had a high mean HAQ score (2.16). Professionals comprised nine nurses, five physiotherapists, five medical doctors, four occupational therapists, and two psychologists.

Patients gave different values to the different items, with each item having a range of importance of 0 or 1 (not at all/a little important) to 3 (very important) (tables 2 and 3 ). This was also true for professionals and controls, though controls designated all domains as being of some level of importance. Items were given maximum importance scores most frequently by controls ( $69.6 \%$ of HAQ ADLs, $82 \%$ of MHAQ domains) and least frequently by professionals $(36.8 \%$ and $54 \%$, respectively). Controls' ratings for the importance of either ADLs or domains were generally the highest and professionals' values were usually the lowest, with patients' ratings lying in between (figs 1,2 , and 3 ).

When the group values for the full $20 \mathrm{HAQ}$ ADLs were totalled (that is, $0-3 \times 25$ subjects) four of the most highly valued ADLs were the same for all groups (toilet, dress, wash, rise) and the least important was the same for every group (reach up) (table 4, ordered by patient scores). However, other ADLs varied widely in position (for example, rise from chair, 8th, 15 th, and 19th) or in the magnitude of their importance (for example, reach up, 18, 33, and 49 points). When the group values for each of the eight domains on the MHAQ were totalled in the same manner, they were ordered identically for all groups (table 5, ordered according to patient scores). Professionals gave the bottom three domains lower values than the other groups.

There was less than slight agreement within each group for importance of both the overall HAQ and the overall MHAQ, which was no 
Table 4. Total importance scores (ranked) for HAQ ADLs (ordered by patient ratings) $(n=25$ in each group)

\begin{tabular}{|c|c|c|c|c|c|c|}
\hline \multirow[b]{2}{*}{$A D L$} & \multicolumn{2}{|c|}{ Health professionals } & \multicolumn{2}{|c|}{$\begin{array}{l}\text { Patients with } \\
\text { rheumatoid arthritis }\end{array}$} & \multicolumn{2}{|c|}{ Non-arthritic controls } \\
\hline & Score & Position & Score & Position & Score & Position \\
\hline On/off toilet & 75 & 1 & 71 & 1 & 75 & 1 \\
\hline Dress & 69 & 3 & 69 & 2 & 72 & 2 \\
\hline Wash body & 63 & 5 & 68 & 3 & 72 & 2 \\
\hline Rise (bed) & 71 & 2 & 61 & 4 & 72 & 2 \\
\hline Walk (flat) & 61 & 6 & 61 & 4 & 65 & 10 \\
\hline Turn taps & 59 & 7 & 58 & 6 & 67 & 7 \\
\hline Shops & 44 & 13 & 58 & 6 & 66 & 8 \\
\hline Stairs & 51 & 9 & 57 & 8 & 64 & 11 \\
\hline Bath & 49 & 10 & 57 & 8 & 72 & 2 \\
\hline Lift cup & 65 & 4 & 56 & 10 & 72 & 2 \\
\hline Chores & 40 & 15 & 55 & 11 & 63 & 13 \\
\hline Reach down & 35 & 17 & 53 & 12 & 60 & 14 \\
\hline Shampoo hair & 40 & 15 & 48 & 13 & 66 & 8 \\
\hline In/out car & 49 & 10 & 48 & 13 & 59 & 15 \\
\hline Rise (chair) & 52 & 8 & 47 & 15 & 51 & 19 \\
\hline Open jars & 47 & 12 & 46 & 16 & 52 & 18 \\
\hline Cut meat & 44 & 13 & 45 & 17 & 64 & 11 \\
\hline Open carton & 33 & 18 & 44 & 18 & 56 & 16 \\
\hline Open car door & 27 & 19 & 42 & 19 & 55 & 17 \\
\hline Reach up & 18 & 20 & 33 & 20 & 49 & 20 \\
\hline
\end{tabular}

$0=$ not at all important; 1 = a little important; 2 = quite important; 3 = very important.

$0-3$ rating $\times 25$ subjects, range $0-75$.

Table 5 Total importance scores (ranked) for MHAQ domains (ordered by patient ratings) ( $n=25$ in each group)

\begin{tabular}{|c|c|c|c|c|c|c|}
\hline \multirow[b]{2}{*}{ Domain } & \multicolumn{2}{|c|}{ Health professionals } & \multicolumn{2}{|c|}{$\begin{array}{l}\text { Patients with } \\
\text { rheumatoid arthritis }\end{array}$} & \multicolumn{2}{|c|}{ Non-arthritic controls } \\
\hline & Score & Position & Score & Position & Score & Position \\
\hline Hygiene/toilet & 74 & 1 & 71 & 1 & 75 & 1 \\
\hline Dress/groom & 70 & 2 & 70 & 2 & 75 & 1 \\
\hline Rise from bed/chair & 65 & 3 & 64 & 3 & 75 & 1 \\
\hline Walk/stairs & 64 & 4 & 62 & 4 & 72 & 4 \\
\hline Eat, prepare food & 62 & 5 & 61 & 5 & 70 & 5 \\
\hline Grip & 50 & 6 & 58 & 6 & 67 & 6 \\
\hline Reach up/down & 46 & 7 & 54 & 7 & 65 & 7 \\
\hline Activity (general) & 40 & 8 & 53 & 8 & 64 & 8 \\
\hline
\end{tabular}

$0=$ not at all important; 1 = a little important; 2 = quite important; 3 = very important.

$0-3$ rating $\times 25$ subjects, range $0-75$.

Table $6 \kappa$ Levels of agreement for importance of function $(n=25$ in each group)

\begin{tabular}{|c|c|c|c|c|}
\hline \multirow[b]{2}{*}{ Groups } & \multicolumn{2}{|c|}{ Simple $\kappa$ values } & \multicolumn{2}{|c|}{ Quadratic weighted $\kappa$ values } \\
\hline & $\begin{array}{l}8 \text { Domain } \\
M H A Q\end{array}$ & $\begin{array}{l}20 A D L \\
H A Q\end{array}$ & $\begin{array}{l}8 \text { Domain } \\
M H A Q\end{array}$ & $\begin{array}{l}20 A D L \\
H A Q\end{array}$ \\
\hline \multicolumn{5}{|l|}{ Single groups: } \\
\hline $\mathrm{RA}($ patients $)(\mathrm{n}=25)$ & 0.09 & $0.04^{\star}$ & $0.244^{\star \star \star}$ & $0.241^{\star \star \star}$ \\
\hline HP (professionals) $(n=25)$ & $0.16^{\star}$ & $0.17^{\star}$ & $0.327^{\star \star \star}$ & $0.241^{\star \star \star}$ \\
\hline NAC (controls) $(n=25)$ & 0.08 & 0.05 & $0.299^{\star \star \star}$ & $0.368^{\star \star \star}$ \\
\hline \multicolumn{5}{|l|}{ Combined groups: } \\
\hline $\mathrm{RA}+\mathrm{HP}(\mathrm{n}=50)$ & $0.11^{\star}$ & $0.10^{\star}$ & $0.275^{\star \star \star}$ & $0.238^{\star \star \star}$ \\
\hline $\mathrm{RA}+\mathrm{NAC}(\mathrm{n}=50)$ & 0.07 & $0.05^{\star}$ & $0.308^{\star \star \star}$ & $0.323^{\star \star \star}$ \\
\hline $\mathrm{HP}+\mathrm{NAC}(\mathrm{n}=50)$ & $0.12^{\star}$ & $0.09^{\star}$ & $0.381^{\star \star \star}$ & $0.365^{\star \star \star}$ \\
\hline \multicolumn{5}{|l|}{ All subject groups: } \\
\hline $\mathrm{RA}+\mathrm{HP}+\mathrm{NAC}(\mathrm{n}=75)$ & $0.10^{\star}$ & $0.08^{\star}$ & $0.326^{\star \star \star}$ & $0.316^{\star \star \star}$ \\
\hline
\end{tabular}

${ }^{\star} \mathrm{p}<0.05 ;{ }^{\star \star} \mathrm{p}<0.01 ;{ }^{\star \star \star} \mathrm{p} p<0.001$.

†Levels of agreement: poor (0); slight (0.01-0.2); fair (0.21-0.4); moderate (0.41-0.6); substantial (0.61-0.8); almost perfect (0.81-1.00).

Table 7 Important disability items spontaneously generated by patients $(n=25)$

\begin{tabular}{|c|c|}
\hline Category (No of citations) & Items \\
\hline Mobility (12) & $\begin{array}{l}\text { Walk, shop, stairs (4), get out of bed, get out of chair (2), reach up (2), } \\
\text { drive car }\end{array}$ \\
\hline Housework (10) & Housework (5), clean windows, hang curtains, iron, vacuum, make bed \\
\hline Cooking/preparing food (10) & Open tins $(7)$, prepare vegetables, ${ }^{\star}$ cook $^{\star}{ }^{\star}$ lift kettle, ${ }^{\star}$ \\
\hline Leisure activities (8) & $\begin{array}{l}\text { Gardening, play guitar, }{ }^{\star} \text { country walking }(2)^{\star} \text { carpentry, }{ }^{\star} \text { get out, }{ }^{\star} \\
\text { hobbies, }{ }^{\star} \text { leisure activities }{ }^{\star}\end{array}$ \\
\hline Personal care (7) & Wash, dress (3), bath, do up buttons, clean teeth` \\
\hline Childcare (3) & Childcare $(3)^{\star}$ \\
\hline Fine movements ( 3 ) & Turn taps (2), turn cooker knob* \\
\hline Work/role (1) & Work $^{\star}$ \\
\hline
\end{tabular}

*Not on HAQ. stronger when any combination of groups was analysed ( $\kappa$ values $<0.17$, table 6 ). When quadratic weighted $\kappa$ values were examined, agreement was slightly higher and had not arisen by chance, but was still only fair ( $\kappa$ values $<0.38$, table 6).

To see whether the HAQ adequately covered items of function important to patients and whether it contained redundant items, patients were asked to generate items of difficulty that were important to them, before seeing the HAQ (table 7). Of the 54 disability items of importance generated by patients, 37 (69\%) were already included in the HAQ. Most of the remaining 17 items related to leisure activities (seven items or $13 \%$ of total patient generated items).

\section{Discussion}

The first aim of the study was to establish whether there is agreement between and within patients with RA, health professionals, and healthy controls on the importance of disability items measured by the HAQ. The mean disability (HAQ) score for these patients with RA was intentionally high, but as this group may not be representative it might have been appropriate to have included some patients with lesser disability.

Individual patients could clearly identify different levels of importance for different functions. The ratings varied between patients and they used a wider range of values than controls. Professionals gave the lowest importance to functions, healthy controls gave the highest, and patients fell between the two. One possible explanation for this difference may be that professionals attach less importance to functions because their training encourages them to teach alternative ways round problems. Healthy controls may be unable to conceive of not being able to do everything and take function for granted. Patients may be making a transition from the inexperienced views of healthy subjects towards the more pragmatic views of professionals. However, professionals may not appreciate that even if there are ways round problems, patients may still desire to do their usual tasks (for example, a shower may be a practical substitute for a bath, but some people prefer bathing to showering). It seems clear, therefore, that taken with the low $\kappa$ levels, neither a population, professional, nor even a patient mean rating for the importance of disabilities is an appropriate weighting system. The continued low level of agreement when groups of subjects are combined shows that not only do patients not have uniform values but also they do not agree with professional or control values. The MHAQ does not yield any better agreement, despite containing broader functional domains than the very specific HAQ questions.

Constant use of the HAQ may have made professionals lose sight of the basic tenetnamely, that it was designed to measure disability alone. Familiarity may lead professionals to assume that an HAQ score has a universal value (for example, a score of 2.5 will mean the same to all patients in practical and 
emotional terms). Secondly, for most professionals an HAQ score conjures up a mental picture of what such a disability means-that is, we feel we know what that universal value is. Finally, in the absence of any other information we assume that the disability is important to the patient. By failing to assess the way a particular functional loss affects the individual patient, we may be guilty of imposing our own judgments upon factual disability scores. The study shows that HAQ items do not have a universal value and that health professional assumptions about values do not accord with patient values.

The second aim of the study was to see whether a well respected disability questionnaire (HAQ) could be used as a basic tool to calculate an impact score. When patients were asked to generate items of disability important to them, most items generated (69\%) were included in the HAQ and although up to $10 \%$ of patients overall place no value on some HAQ items, no HAQ item was consistently deemed unimportant. Leisure activities were the only significant items of importance to patients omitted from the HAQ. The items in the HAQ were appropriately chosen to represent function, but it appears to contain a large number of the items deemed important by patients, reassuring us of its validity in measuring relevant disability, and a sufficient number for it to be used as a basis for capturing the impact of disability.

The study data suggest three ways in which a measure of the impact of disability on patients might be developed. These are $(a)$ to create a new measure that includes leisure items; $(b)$ to add an open question to the HAQ for the patient to insert their important leisure items; or (c) to accept this limitation of the HAQ for measuring impact but still use it as a basis for the new impact tool. It would be inappropriate to develop a new functional measure as a basis for calculating impact when the HAQ is a well validated and internationally respected functional measure covering $70 \%$ of items important to patients. Adding an open question for the purpose of calculating impact would cause interpretation problems as there would be no corresponding difficulty score, the topic of the open question would have to be inserted when the scale was re-administered, and it is not obvious how the open question should be handled if the previously designated topic was no longer important but a new problem had arisen. This has been recognised as a difficulty with other scales which include items specified by individual patients. ${ }^{34}$ On balance it would seem appropriate to use the HAQ as a basis for an impact measure as it covers most items important to patients, but acknowledging the gap left by leisure activities.

A small change in a function score can be clinically significant for the patient but not statistically significant. ${ }^{35}$ Clinical significance for the patient must mean that something of personal importance to them has occurred. The personal impact of disability has been described as "the degree to which it disrupts the life situation", ${ }^{36}$ though life disruption may

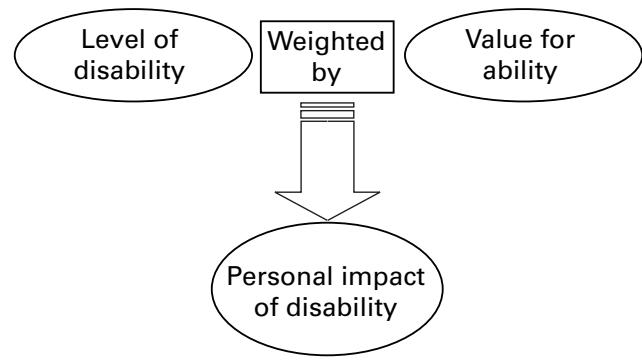

Figure 4 Proposed model for calculating the personal impact of disability.

not depend on disability alone. Assessment of disability is currently measurement of fact (assuming the HAQ to reflect actual disability), but for the patient self assessment of difficulty is made in the context of personal circumstances, something that has been lost in standardised disability measurement. ${ }^{37}$

We therefore propose a model whereby the personal impact of disability is an interaction between disability for ADLs and the belief that the ability to perform those ADLs is important (or valued) by the patient. ${ }^{38}$ One method of calculating personal impact would be to weight the level of difficulty for each ADL by the patient's opinion of the importance of being able to perform that ADL (fig 4). Creating separate profiles of disability and importance (rather than a weighted scale) would not aid the interpretation of disability, as it is only when difficulty occurs in a personally important ADL that it is likely to impact upon the patient.

The principle of weighting has been explored elsewhere. The problem elicitation technique $^{39}{ }^{40}$ was developed from the MacMaster Toronto arthritis patient preference disability questionnaire ${ }^{34}$ but is administered by an interviewer, making it less convenient. The PARIS sectogram weights three symptoms in osteoarthritis $^{41}$ (although the weights are relative to each other), whereas weighted scales have been used in general rehabilitation. ${ }^{42}$ Conceivably, the addition or removal of mean weights in a scale may not make large differences to the validity and sensitivity, but the use of individualised weights may be more important in this respect.

Using a personal impact score to complement (but not replace) a disability score will provide a method of differentiating between the impact of disability in patients with similar disability levels and allow recognition of the impact of a relatively minor disability in some patients. It will help to inform decisions on intervention, in the assessment of clinical trials of treatments, and to determine whether a treatment affects disability in a meaningful way for patients. It will allow us to justify the expense of treatments according to the benefit perceived by a patient rather than the assumed benefit and may help to identify patients at risk from reduced psychological wellbeing or depression. More importantly, it will help us to understand the patient better.

Concepts of outcome measurement underwent a major shift into patient centred assessment by the publication of the HAQ and it is now time to place the measurement of 
disability within the patient's value system. The development of tools measuring patient values or important changes in function has long been advocated in arthritis, ${ }^{16}{ }^{43-45}$ and this study provides further evidence of the need to measure the impact of disability on individual patients and justifies using the HAQ as an appropriate basic tool. A model of the personal impact of disability is proposed: disability weighted by the importance or value for that disability to an individual patient. Further work is under way to develop and validate such a measure of the personal impact of disability.

The authors thank statisticians Dr Barnaby Reeves and Rosemary Greenwood (University of Bristol Research and Development Support Unit) for their advice on the use of $k$ measures of agreement; the Arthritis Research Campaign for its support; and patients, professionals and volunteers for their participation.

1 Fries JF, Spitz P, Kraines RG, Holman HR. Measurement of patient outcome in arthritis. Arthritis Rheum 1980;23:137-45.

2 Meenan RF, Gertman PM, Mason JM. Measuring health status in arthritis: the Arthritis Impact Measurement Scale. Arthritis Rheum 1980;23:146-53.

3 Young A, Dixey J, Cox N, Davies P, Devlin J, Emery P, et al. How does functional disability in early rheumatoid arthritis affect patients and their lives? Results of the 5 years follow-up in 732 patients from the early RA study (ERAS). Rheumatology (Oxford) 2000;39:603-11.

4 World Health Organisation. International Classification of functioning, disability and health (ICIDH-2). http:/ functioning, disability and health

5 Kirwan JR, Reeback JS. Stanford Health Assessment Questionnaire modified to assess disability in British patient with rheumatoid arthritis. Br J Rheumatol 1986;25:206-9.

6 Ramey DR, Raynauld JP, Fries JF. The Health Assessment Questionnaire 1992: status and review. Arthritis Care Res 1992; 5:119-29.

7 Carr AJ, Thompson PW, Young A. Do health status measures have a role in rheumatology? [abstract]. $\mathrm{Br}$ Rheumatol 1997;36(suppl 1):149.

8 Felson DT, Anderson JJ, Boers M, Bombardier C, Chernoff M, Fried B, et al. The American College of Rheumatology preliminary core set of disease activity measures for rheumatoid arthritis clinical trials. Arthritis Rheum 1993; 36:729-40

9 Pincus T, Summey JA, Soraci SA, Wallston KA, Hummon NP. Assessment of patient satisfaction in activities of daily living using a modified Stanford Health Assessment Quesliving using a modified Stanford Health Asses

10 Hewlett S, Young P, Kirwan JR. Dissatisfaction, disability and rheumatoid arthritis. Arthritis Care Res 1995;8:4-9.

11 Giorgino KB, Blalock SJ, DeVellis RF, DeVellis BM, Keefe FJ, Jordan JM. Appraisal of and coping with arthritis related problems in household activities, leisure activities and pain management. Arthritis Care Res 1994;7:20-8.

12 Berkanovic E, Hurwicz ML, Lachenbruch PA. Concordan and discrepant views of patients' physical functioning. Arthritis Care Res 1995;8:94-101.

13 Kwoh CK, O'Connor GT, Regan-Smith MG, Olmstead EM, Brown LA, Burnett JB, et al. Concordance between clinician and patient assessment of physical and mental health status. J Rheumatol 1992;19:1031-7.

14 Fischer D, Lorig K, Laurent D, Holman H. Patient assessment of clinical change is a reliable and sensitive measure and is not unduly biased by baseline patient expectations [abstract]. Arthritis Rheum 1995;38 (suppl): S178.

15 Hewlett S, Kirwan JR. Discrepancies between actual and perceived change in function in rheumatoid arthritis are not a function of memory [abstract]. Br J Rheumatol 1998; 37( (suppl 1):177

16 Blalock SJ, DeVellis BM, DeVellis RF, Giorgino KB, Van $\mathrm{H}$ Sauter S, Jordan JM, et al. Psychological well-being among people with recently diagnosed rheumatoid arthritis: do self-perceptions make a difference? Arthritis Rheum 1992; 35:1267-72.

17 Katz PP, Yelin EH. Life activities of persons with rheumatoid arthritis with and without depressive symptoms. Arthritis Care Res 1994;7:69-77.
18 Katz PP, Yelin EH. The development of depressive symptoms among women with rheumatoid arthritis. symptoms among women with

19 Egger MJ, Ward JR, Karg MB, Williams HJ, Reading JC, and the Co-operative Systematic Studies of Rheumatic Diseases. Reliability and validity of the CSSRD Functional Assessment Survey in rheumatoid arthritis. Arthritis Care Res 1995;8:21-7.

20 Harwood RH, Gompertz P, Ebrahim S. Handicap one year after stroke: validity of a new scale. J Neurol Neurosurg Psychiatry 1994;57:825-9.

21 Dolan P, Gudex C, Kind P, Williams A. A social tariff for EuroQol. York: Publications Unit, Centre for Health Economics, University of York, 1996.

22 Slevin M, Plant H, Lynch D, Drinkwater J, Gregory W. Who should measure quality of life, the doctor or the patient? $\mathrm{Br}$ J Cancer 1988;57:109-12.

23 Rothwell PM, McDowell Z, Wong CK, Dorman PJ. Doctors and patients don't agree: cross-sectional study of patients' and doctors' perceptions and assessments of disability in multiple sclerosis. BMJ 1997;314:1580-3.

24 Cockshott Z, Hewlett S, Kirwan JR, Haslock I, Stamp J. Do health professionals and patients agree on disease management strategies? [abstract]. Br J Rheumatol 1997;36(suppl 1):415.

25 Lubeck DP, Yelin EH. A question of value: measuring the impact of chronic disease. The Millbank Quarterly 1988;66:444-64.

26 Stensman R. Severely mobility-disabled people assess the quality of their lives. Scand J Rehab Med 1985;17:87-99

27 Balaban DJ, Sagi PC, Goldfarb NI, Nettler S. Weights for scoring the Quality of Well-being instrument among rheumatoid arthritics. Med Care 1986;24:(11)973-80.

28 Wolfe F, Hawley DJ. Measurement of the quality of life in rheumatic disorders using the EuroQol. Br J Rheumatol 1997;36:786-93.

29 Redelmeier DA, Lorig K. Assessing the clinical importance of symptomatic improvements. Arch Intern Med 1993; 153:1337-42.

30 Wells GA, Tugwell P, Kraag GR, Baker PR, Groh J, Redelmeier DA. Minimum important difference between patients with rheumatoid arthritis: the patient's perspective. J Rheumatol 1993;20:557-60.

31 Arnett FC, Edworthy SM, Bloch DA, McShane DJ, Fries JF, Cooper NS, et al. The American Rheumatism Association 1987 revised criteria for the classification of rheumatoid arthritis. Arthritis Rheum 1988;31:315-24.

32 Siegal S, Castellan NJ, eds. Non-parametric statistics for the behavioural sciences. Singapore: McGraw-Hill, 1988:28491

33 Streiner DL, Norman GR, eds. Health measurement scales. Oxford: Oxford University Press, 1989:79-96.

34 Tugwell P, Bombardier C, Buchanan WW, Goldsmith G, Grace E, Bennett KJ, et al. Methotrexate in rheumatoid arthritis: impact on quality of life assessed by traditional standard item and individualized patient preference health status questionnaires. Arch Intern Med 1990;150:59-62.

35 Liang MH. The historical and conceptual framework for functional assessment in rheumatic disease. J Rheumatol 1987;14(suppl 15):2-5.

36 Shontz FC, ed. In: The psychological aspects of physical illness and disability. New York: MacMillan, 1975:57.

37 Carr AJ. A patient-centred approach to evaluation and treatment in rheumatoid arthritis: the development of a clinical tool to measure patient-perceived handicap. Br J Rheumatol 1996;35:921-32.

38 Hewlett S. Values, disability and personal impact in rheumatoid arthritis. Bristol: University of Bristol: 2000. (PhD thesis.)

39 Bell MJ, Bombardier C, Tugwell P. Measurement of functional status, quality of life and utility in rheumatoid arthritis. Arthritis Rheum 1990;33:591-601.

40 Buchbinder R, Bombardier C, Yeung M, Tugwell P. Which outcome measures should be used in rheumatoid arthritis clinical trials? Arthritis Rheum 1995;38:1568-80.

41 Bellamy N, Wells GA, Campbell J. PARIS sectogram: a method for weighting and aggregating the WOMAC osteoarthritis index. Osteoarthritis Cartilage 1994;2:(suppl 1):37.

42 Laman H, Lankhorst GJ. Subjective weighting of disability: an approach to quality of life assessment in rehabilitation. an approach to quality of life asses

43 Meenan RF, Pincus T. The status of patient status measures. J Rheumatol 1987;14:411-14.

44 Long AF, Scott DL. Measuring health status and outcomes in rheumatoid arthritis within routine clinical practice. Br J Rheumatol 1994;33:682-5.

45 Carr AJ, Thompson PW, Kirwan JR. Quality of life measures. Br J Rheumatol 1996;35:275-81. 